Revista Iberoamericana, Vol. LXXX, Núm. 246, Enero-Marzo 2014, 227-240

\title{
ALEJANDRA PIZARNIK, UN EJEMPLO DE CORRECCIÓN SÁDICA
}

\author{
POR \\ Mariana Di Ció \\ Université Paris III - Sorbonne nouvelle
}

Las palabras cierran todas las puertas.

Lo que se ve, lo que se va, es indecible.

“Figuras del silencio" (APP B.5; f.2A)

Los papeles de trabajo de Alejandra Pizarnik reflejan la naturaleza opaca y por momentos huidiza de su voz: abundantes auto-instrucciones para pautar y ordenar el trabajo y un sinnúmero de inventarios léxicos, de variantes y de palabras que se amontonan, que se superponen, que se anulan entre sí hasta volverse, paulatinamente, figuras del silencio: "una tribu de palabras mutiladas/busca asilo en mi garganta”(Poesía 181). En tanto reverso de los textos publicados o "visibles", ${ }^{1}$ el análisis de los archivos de un escritor supone a la vez una valoración de lo elidido (lo tachado, lo borrado, lo descartado) y de lo residual (anotaciones marginales, dibujos, flechas, y todos aquellos "detritus textuales" que sobreviven a la corrección y que logran enclavarse en el texto final), según una lógica análoga al paradigma de inferencias indiciales desarrollado por Carlo Ginzburg (1986). En otras palabras, al poner el acento en el "taller" de escritura como lugar paradójico de la enunciación, la perspectiva genética permite un acercamiento a la obra sin la trampa de la interpretación en clave autobiográfica. Permite, también, identificar campañas de escritura y restablecer una cronología aproximativa para el proceso de composición (Hay 1993), proceso que, en el caso de Pizarnik, resulta indisociable de la corrección frenética y de la reescritura: "Escribí tres poemas. Sometí al último a una serie de retoques. Sí, es eficaz el hacerlo: se siente cada palabra como un cuchillo de doble filo. [...] Mi tercer poema tenía quince ‘que’. Luego los reduje a seis”; “No sé por dónde comenzar a reescribir mis escritos pulverizados” (Diarios 83, 458).

El objetivo de este trabajo es examinar, a partir de un ejemplo concreto, las sucesivas etapas de corrección y de reescritura a las que Pizarnik somete sus textos, para

1 Retomo, por supuesto, la dicotomía empleada por Borges (450) al inventariar las obras de Pierre Menard. 
reconsiderar la idea bastante aceptada (y a veces, incluso, hasta fomentada por la misma autora) de una escritura que sería "automática" o espontánea, fruto de la "inspiración" más que de la transpiración que suponen las largas y penosas etapas de corrección. ${ }^{2}$ Una vez presentado el Fondo Alejandra Pizarnik, me detendré primero en tres mecanismos que en general aparecen combinados y que cumplen un rol central en este proceso de transformación de los textos: la selección, la tachadura y el borrado, para luego ilustrar, a la luz del dossier genético del sexto poema de la serie “Los pequeños cantos", el modo en que Pizarnik vapulea, maltrata y mutila sistemáticamente sus textos, mediante un engranaje de mecanismos de corrección que Barthes calificará de "maquinita sádica" (Herchberg Pierrot, "Les manuscrits” 191).

Los archivos de Alejandra Pizarnik se conservan en el Departamento de Manuscritos de la Biblioteca de la Universidad de Princeton: si bien existen importantes lagunas en la última etapa, registran el inicio de la vida pública de su autora (aproximadamente desde el año 1954) y se prolongan hasta el momento de su muerte, en 1972. Son unas diez cajas organizadas por series a partir de su contenido, ${ }^{3}$ que dejan al descubierto una tensión constante entre mostrar y ocultar, entre decir y callar. A pesar de las numerosas oportunidades en que Pizarnik se refiere a la destrucción de sus manuscritos, ${ }^{4}$ lo cierto es que contamos con una buena cantidad de borradores, de notas de lectura y de material preparatorio, de proyectos de textos poéticos y de ensayos que no sólo revelan la necesidad de guardar registro o de documentar la propia práctica sino también de conservar el material descartado para futuras utilizaciones o reelaboraciones. De alguna manera, el caos de papeles y de cuadernos resulta metonimia de muchos temas centrales de la obra de Pizarnik (el reinado de las sombras y de la melancolía, la lucha cuerpo a cuerpo con el lenguaje, la pérdida como preanuncio de la muerte...), a la vez que pone en evidencia el movimiento mismo de su escritura, que por supuesto incluye interrupciones, borrones, vacilaciones y tachaduras de todo tipo.

En ese sentido, es interesante señalar que Pizarnik tiende a acompañar las alusiones a la materialidad de los soportes o instrumentos de escritura con comentarios metapoéticos, como si existiera una analogía entre los soportes y las operaciones textuales que

2 Cabe aclarar que, sin hacer un análisis puntual de poemas, tanto Alicia Genovese (10) como César Aira (15-16) habían señalado ya la falacia interpretativa de la supuesta escritura automática de Pizarnik.

3 I. Diarios; II. Cuadernos; III. Escritos (a. Poesía; b. Ficción; c. No ficción); IV. Correspondencia; V. Arte; VI. Material impreso; VII. Miscelánea.

4 "Ayer he roto alrededor de cien poemas y prosas. He quedado asombrada de mi falta de calidad poética, mis gritos, mi exasperación. Hay que empezar de nuevo. Además, me quedan doscientos poemas más que seguramente romperé" (Diarios 142).

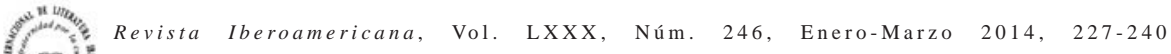
ISSN 0034-9631 (Impreso) ISSN 2154-4794 (Electrónico) 
conducen a esta escritura en movimiento: "Es extraño. Mi estudio sobre el poema en prosa se altera por no saber si usar una carpeta u hojas sueltas para realizarlo" (Diarios 420); como si, además de hacerse eco de las interrupciones y dificultades inherentes al proceso de escritura, los soportes tuvieran una incidencia real en el fluir de los textos: “[mi tío Armand] mandó un solo Cahier le Bea, y poquísimas hojas (que no le pedí tan llenas de marcas de agua; ahora habrá que secar las hojas antes de escribir)” (Pizarnik Correspondencia 214); “Al azar de la máquina de escribir surgen prosas que son una muestra de lenguaje errante” (Diarios 480).

Además de su principal rol (albergar palabras), los soportes inciden en la distribución espacial y plástica de los textos y, en ese sentido, también admiten una lectura alegórica, de manera tal que la manipulación y la disposición de papeles y cuadernos remeda o anuncia la “conquista” o “apropiación” de textos en vistas a una reelaboración ulterior, la "migración” de un fragmento hacia otros contextos, o incluso la estratificación o superposición de “capas textuales”. Hay, en Pizarnik, un evidente esfuerzo por poner en valor la dimensión plástica y visual de los manuscritos, tal como se desprende de las numerosas tentativas de puesta en página, de los grafismos que balizan el avance de los textos (en general, la "P” mayúscula, pero en ocasiones también "pasar a máquina” o “machine”), del empleo de tintas de diferentes colores, de la mezcla entre escritura dactilográfica y manuscrita, del uso del pizarrón o de la profusión de ganchitos y de marcas de cinta scotch que advertimos en sus papeles, entre otros dispositivos tendientes a realzar la visualización. ${ }^{5}$ Porque materializan los hábitos de trabajo y las inquietudes estéticas de Pizarnik, todas esas intervenciones sobre el soporte dan cuenta de una conquista del material, así como de una puesta en marcha -y en escena- de la escritura. En otras palabras, si la materialidad de los manuscritos repite el imaginario simbólico que de ella se desprende (estamos ante una estética de lo heterogéneo, de lo discontinuo, de lo fragmentario), también el discurso metapoético de la autora va en el mismo sentido:

Busco una forma definitiva, un estilo simple y correcto de decir las cosas. Esto me enerva. Es como mi imposibilidad de encontrar una lapicera exactamente apta al movimiento de mi mano. A veces creo encontrarla pero me sirve por muy poco tiempo. El mismo problema con los cuadernos, con las hojas. Mi deseo es inhumano: busco una continuidad absoluta. Lo único continuo en mí es mi deseo de esta imposible continuidad. Ahora recuerdo que ni siquiera mi estilo oral es siempre el mismo: cambio de voz, cambio de léxico, cambio de acento (recuerdo mi período mexicano en París, lo que me gustaba acentuar diferentemente las palabras). Estoy anómalamente fragmentada. Por eso mis pequeños poemas. (Diarios 359)

5 Para un análisis más detallado de mecanismos de materialización e instrumentalización de la lengua en Pizarnik, y en particular de la interacción entre codicología y metapoética, ver Di Ció.

Revista Iberoamericana, Vol. LXXX, Núm. 246, Enero-Marzo 2014, $227-240$
ISSN 0034-9631 (Impreso) 
Aunque el valor de un manuscrito no se mida en relación con la cantidad de anulaciones que encierra, el análisis de tachaduras y variantes permite entrever o intuir la intensidad de los procesos de construcción del andamiaje verbal y el modo en que la autora modula el grado de legibilidad y de opacidad de sus textos. Ávida lectora de Mallarmé, Pizarnik es particularmente sensible al "misterio en las letras" (Divagations 283) de tinteros oscurecidos por las sombras y por la noche, a la ininteligibilidad que se esconde detrás de cada signo impenetrable: no sólo no ignora el valor simbólico de las tachaduras sino que, como se desprende de su correspondencia con Antonio Requeni, parece ver en ellas la garantía de una percepción total, de una aprehensión más profunda y perfecta de su secreto: "Dicen que Rabindranath Tagore descubría formas divinas en sus tachaduras” (Requeni 211). Desde esa óptica, lo tachado sería no sólo una fuerza encubierta que, aun ausente de la superficie textual, seguiría ejerciendo su influencia o incluso fomentaría la aparición del sentido, sino la esencia misma de la literatura, según la célebre fórmula de Barthes (“La littérature, c’est la rature”), que la crítica genética disloca en mandato: "Lis tes ratures" (de Biasi 18).

Lejos de exponer un "accidente" de la escritura, la presencia de lo tachado supone la mirada reprobatoria, la autocensura por parte del sujeto que no sólo escribe sino que también relee su obra -en el caso de Pizarnik, a menudo en clave metapoética: "Antiguamente mis ojos buscaron refugio en las cosas humilladas, desamparadas, pero en amistad con mis ojos he visto, he visto y no aprobé” (Poesía 286). Supone, también, un gesto de selección, que las tachaduras materializan gráficamente; de manera algo darwiniana, se suprime o se descarta aquello que no posee cualidades suficientes como para ser retenido, se oculta un término en beneficio de otro, hasta que, poco a poco, "la palabra deseada" (Prosa 300) se va haciendo lugar entre las líneas de tinta. Se trata de una presencia que, junto con la exaltación de la voluptuosidad material del texto, también pone en evidencia la sensualidad y el placer de la escritura pero, tal como lo advierte Roland Barthes, también el placer de fisgonear lo tachado:

\section{Corrections}

On barre d'un côté, on ajoute de l'autre, on dessine des trous et des retombées ; au texte plat du début, on adapte une petite machine sadienne : on aveugle et on fait éclater, on éventre et on fait gicler. Qui douterait de la sexualité de l'écriture ? Tout le monde voudrait bien savoir ce qu'il y avait sous mes ratures : c'est le noir que d'abord on veut lire. (Ms de Roland Barthes par Roland Barthes, « Légendes / Images avant le texte », IMEC, BRT2. A-17. 01. 01, citado por Herschberg Pierrot, “Les manuscrits” 191)

Es interesante notar que, al asociar tortura y placer en la escritura, Barthes reanuda con una concepción del trabajo del escritor como mártir, cuyo ejemplo más acabado sería Flaubert, que corrige de manera despiadada y obsesiva, y que encarna la idea de creación como un verdadero descenso a los infiernos de la composición, como le

Revista Iberoamericana, Vol. LXXX, Núm. 246, Enero-Marzo 2014, $227-240$
ISSN 0034-9631 (Impreso) 
gustaba señalar a Borges (265); y Bioy Casares (1407-08). En ese sentido, al insinuar el voyeurismo y aludir a la corrección como una "maquinita sádica", Barthes no hace sino reforzar la idea de la corrección excesiva como un vicio malsano y como fuente de sufrimiento, una idea que por supuesto resulta atractiva para alguien como Pizarnik, que admira y hasta enaltece una figura tan polémica como la de la condesa sangrienta: "Yo 'civilizo' mis poemas al detenerlos y congelarlos. Pero todo este trabajo infernal que me doy para escribir notas” (Diarios 416); “Terror de cosificar la obra. ¿Y por qué no lo haría? Vínculo sádico. La desmenuzo, la fragmento” (Diarios 485).

A pesar de estos reparos, resuenan en la obra de Pizarnik varios sintagmas que sugieren una concretización de la lengua, tales como "la casa del lenguaje”, "la pequeña casa del canto", el "espléndido palacio de papel de las peregrinaciones infantiles" o la “casa de citas” (Poesía 223, 435, 287; Prosa 69) donde, jugando con la idea de maison close, propone una mirada irónica e irreverente de la operación intertextual. Al igual que el Palais du vocabulaire, una serie de cuadernos (APP B.4, f.5; B.4, f.7; B.5, f.6) donde Pizarnik copiaba y/o pegaba citas desmenuzadas de distintas fuentes, suerte de "limbo textual" o reservorio de palabras que en ocasiones volvemos a encontrar -mutiladas, transformadas, fago-citadas- en la obra publicada, estas denominaciones tienden a materializar el lenguaje, a convertir las palabras en una especie de "materia prima" o de "material expresivo" que permitiría construir "monumentos poéticos": "Y he sufrido con las palabras de hierro, con las palabras de madera, con las palabras de una materia excepcionalmente dura e imposible" (Diarios 189); "Cuando a la casa del lenguaje se le vuela el tejado y las palabras no guarecen, yo hablo” (Poesía 223).

$\mathrm{Al}$ albergar una pluralidad de voces exogenéticas y dejar al descubierto la heterogeneidad enunciativa de su obra, esta serie de cuadernos vuelve palpables muchos de los procedimientos de supresión o de borrado feroz vinculados con la práctica de la corrección tal como la entiende Pizarnik, entre los que podemos mencionar:

a) el borrado de referencias contextuales, y una tendencia a la "universalización" de las situaciones poéticas tratadas:

Cuando yo corrijo, explico y traduzco (para ganarme la calificación, quizás, de criatura racional o intelectual). Sin embargo, mi manera de corregir me parece un gran hallazgo. Debiera perseverar en ella. Gracias a ella, separo la imagen de las fantasías ocasionales o escoria o distracción. (Diarios 417)

b) la "autocensura” ejercida sobre ciertos temas: "cantidad de imágenes de muerte y de nacimiento han desaparecido", escribirá en un proyecto de introducción (“Intento de prólogo al estilo de ellos (no del mío)”) que, curiosamente, también será descartado (Prosa 300);

c) el escamoteo de fuentes y el ocultamiento o disimulación de ciertas referencias intertextuales. Así, por ejemplo, encontramos en el Palais du vocabulaire una cita del

Revista Iberoamericana, Vol. LXXX, Núm. 246, Enero-Marzo 2014, 227-240 
poema "El contorno" de Nelly Sachs, en versión española de Rodolfo Alonso: “un anillo girando / que perdió su dedo. / [...] / La caligrafía de las sombras como herencia” (APP B.3, f.9, p. 168), que Pizarnik retoma, después de haberla desvalijado debidamente, en Los poseídos entre lilas: "No necesito sugerencias acerca de grandes epílogos. Estoy hablando, o mejor dicho, estoy escribiendo con la voz. Es lo que tengo: la caligrafía de las sombras como herencia” (Prosa 179).

En tanto tematiza el proceso compositivo y anuncia un ámbito de sombras que impregna el plano semántico, la presencia del verso de Sachs en la obra de Pizarnik también puede leerse como una declaración de principios estéticos. Aún cuando esté encubierta, la incorporación de toda cita supone un "cortar y pegar” previo, o la puesta en práctica de las operaciones que Jakobson calificará de selección y de combinación, muchas veces sometidas luego a operaciones de desplazamiento, de apropiación, de desvío, de recontextualización.

En ese sentido, cabe señalar que los gestos de selección se multiplican en la fase de preparación del poema, y que la entrada en materia comienza, de manera casi inevitable, por una reflexión sobre el lenguaje mismo, y sobre los actos de lectura y de escritura en particular. Es así como, además del análisis pormenorizado de las normas lingüísticas más elementales, vemos aparecer listas de palabras escogidas (enumeraciones de sinónimos o de verbos pertenecientes al mismo campo léxico, “despliegue” sistemático de paradigmas...), a menudo complementadas por un programa de lecturas cuyo objetivo sería compensar un saber lingüístico y literario percibido por la propia Pizarnik como insuficiente.

Si bien es poco lo que sabemos de los criterios que rigen el "recorte” y la "selección” de párrafos, versos o sintagmas de las fuentes más variadas para conformar este liber libris, está claro que la copia adquiere, en tanto parte del trabajo de preparación a la escritura, un estatuto aparte. Se trata, en realidad, de un acto mediante el cual el scriptor lucha contra la página en blanco, apropiándose, en cierta medida, de lo que copia, a la vez que entabla un diálogo con la tradición y consigo misma. En otras palabras, el trabajo de Pizarnik a partir de citas y de palabras previamente seleccionadas supone una conquista del espacio en blanco: no tanto para ganarle terreno al silencio sino para avanzar sobre lo anterior, sobre lo ya dicho, o incluso sobre lo dicho hasta el hartazgo; para elegir cuidadosamente lo que se retiene y descartar aquello que está en demasía, tal como lo sugiere Barthes en el prefacio a sus Essais critiques:

L'écrivain n’a donc nullement à “arracher” un verbe au silence, comme il est dit dans de pieuses hagiographies littéraires, mais à l'inverse, et combien plus difficilement, plus cruellement et moins glorieusement, à détacher une parole seconde de l'engluement des paroles premières que lui fournissent le monde, l'histoire, son existence, bref un intelligible qui lui préexiste, car il vient dans un monde plein de langage, et il n'est rien d'autre que trouver ce code tout fait et devoir s'en accommoder. On entend souvent dire

Revista Iberoamericana, Vol. LXXX, Núm. 246, Enero-Marzo 2014, $227-240$
ISSN 0034-9631 (Impreso) 
que l'art a pour charge d'exprimer l'inexprimable : c'est le contraire qu'il faut dire (sans nulle intention de paradoxe): toute la tâche de l'art est d'inexprimer l'exprimable, d'enlever à la langue du monde, qui est la pauvre et puissante langue des passions, une parole autre, une parole exacte. (15)

Es a partir de este enfoque que, a mi modo de ver, debemos entender los tres mecanismos de "sustracción" (selección, tachado, borrado) que nos ocupan aquí. Es también en ese sentido que debe leerse una entrada de su diario donde Pizarnik se refiere a la lucha contra el bloqueo y la angustia de la página en blanco: "No sé por dónde empezar a escribir. El vacío. Apollinaire aconsejaba para vencer el vacío escribir una palabra, luego otra y otra hasta que se llene” (Diarios 27). La voluntad de retomar la propuesta de Apollinaire es, en sí misma, significativa: el “ennegrecimiento” de la página implica una instancia de "conquista del material", un "llenado" esencialmente físico que consiste en combatir el bloqueo de la escritura a partir de la escritura misma, que es luego sometida a sucesivas etapas de corrección brutal: "cuando escribo sin cálculos retóricos mi prosa tiene un ritmo peculiar: violento y decidido. Intentar embellecer esa prosa mediante correcciones y sustitución de palabras implica deshacer, en parte, ese ritmo. He aquí el problema" (APP B.2; f.2). El modo en que Pizarnik enmienda o "repara" sus textos ${ }^{6}$ implica, en efecto, una amputación que, en función de su ferocidad y de su violencia, podríamos calificar, siguiendo a Barthes, de "sádica", según intentaremos ilustrar a partir del análisis genético de un texto de la serie "Los pequeños cantos”.

Hay, en el cuaderno "Linus" (APP B.3, f.8), una primera versión en prosa, a la que le siguen por lo menos cinco reescrituras en verso, de un texto cuya versión definitiva apareció en el N 45 de la revista Árbol de fuego, publicada en Caracas, en 1971 (Poesía 384). El estudio de las seis versiones de las que disponemos nos permite descubrir la intimidad de una escritura espontánea y fluida, de una escritura orientada hacia lo implícito, que se pule y se perfecciona de manera progresiva, que se hace cada vez más escueta, que se encamina hacia el estilo lacónico y acendrado que caracteriza a una gran parte de los textos de Pizarnik.

Las primeras transformaciones del texto afectan la redistribución de las palabras en la página: a grandes rasgos, cada frase de la primera textualización se transforma en una estrofa en la segunda versión donde, a pesar del uso moderado de la puntuación, la “respiración” del texto ocupa un lugar cada vez más central.

6 "Se ha dicho que el poeta es el gran terapeuta. En este sentido, el quehacer poético implicaría exorcizar, conjurar y, además, reparar. Escribir un poema es reparar la herida fundamental, la desgarradura” (Prosa $312)$.

\footnotetext{
Revista Iberoamericana, Vol. LXXX, Núm. 246, Enero-Marzo 2014, 227-240 ISSN 0034-9631 (Impreso) ISSN 2154-4794 (Electrónico)
} 
Versión 1 : Cahier LINUS [Alejandra Pizarnik Papers [APP], Princeton University Library, Rare Books and Special Collections, Manuscripts Department [C0395], Box 3, Folder 8, p. 5]

anulado

Al sol de la infancia tenía mi tuve una voz nueva, infusa de muerte, de vida hermosa. Los del pasaje de los falsos silencios me separaron.

P Yace violentamente inmóvil en mi garganta: El desaparecido de los siete rostros, El músico.

No comprendo negras garras asidas a (me asfixio) la roca hostigada por los vientos. No quiero otro abrigo para mis frases harapientas que mi memoria Noches de Saint-Paul-de-Vince, grietas en los muros fueron negros sortilegios, fueron poemas aciagos.

Versión 2: Cahier “Meridiano” [APP, loc. cit., Box 4, Folder 6, p. 39]

al sol de la infancia tuve una voz nueva, mía, infusa de amor muerte, de amor, de vi da hermosa

los del corazón del hueco nocturno los del paraje de los falsos silencios me separan de mis palabras

violentamente inmóvil en mi garganta

aquí yace

los

el tesaparecido de łos siete rostros, el músico,

no comprendo

negras garras asidas a

(me asfixio) la roca hostigada por los vientos

para mis frases desolladas que

no quiero otro abrigo

la memoria noches

de Saint-Paul-de-Vince

grietas en los muros

fueron negros sortilegios

fueron poemas aciagos

24) Revista Iberoamericana, Vol. LXXX, Núm. 246, Enero-Marzo 2014, 227-240

ISSN 0034-9631 (Impreso) $\quad$ ISSN 2154-4794 (Electrónico) 


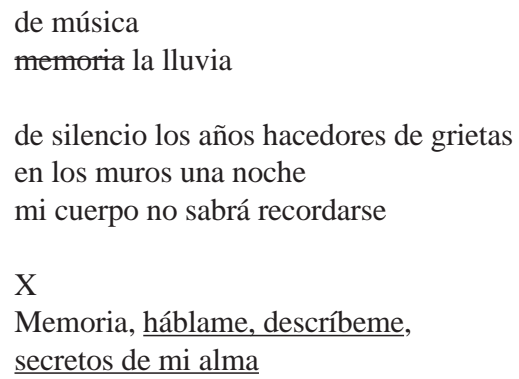

Lejos de ser un cambio insignificante, esta modificación de la prosodia deja en claro el hecho de que, para Pizarnik, la prosa no es (como pretendía el maestro de filosofía de El burgués gentilhombre), algo que simplemente se opone al verso, sino más bien un avatar de la cadencia, una manera de manifestar el ritmo interno que rige la distribución de palabras en la página en blanco:

Deseo estudiar muy seriamente el poema en prosa. No comprendo por qué elegí esta forma. Se impuso. Además, está en mí desde mi libro primero. Nunca leí nada al respecto. Poemas en prosa abiertos (con silencios) y cerrados, compactos y casi sin puntos y aparte. Poemas en prosa muy breves, breves como aforismos (Rimbaud : Phrases). [...] En el poema en prosa los espacios son necesarios (cada párrafo una frase como las de Rimbaud. O varias frases. Pero todo dentro de tres o cuatro líneas. Y con espacios dobles. En caso contrario hay que olvidarse de la economía del lenguaje y escribir del modo más fluido que existe: Miller). [...]

Poemas en prosa: necesidad de los espacios dobles. Al menos, para mi “estilo” (Diarios 418-19)

Si bien hay otros textos en donde encontramos esta misma labilidad entre el verso y la prosa -así lo vemos, por ejemplo, en el trabajo preparatorio para "Linterna sorda" (APP B.4, f.6, p. 22, p. 23, p.25, p.26, p.27 y Poesía 215)-, no deja de llamar la atención el hecho de que Pizarnik oscile tan explícitamente entre estas dos formas de expresión, volviendo en ocasiones a la prosa luego de varios intentos en verso. También en este aspecto parece seguir los pasos de Apollinaire que, a través de la desarticulación de la prosa a favor del verso libre y del borrado sistemático de los signos de puntuación, habría transformado un cuento ("El obituario") en poema ("La casa de los muertos”), o al menos haber dudado lo suficiente acerca del estatuto de cada uno de estos dos textos (Follet). Por otro lado, la política de supresión y del borrado despiadado que advertimos en estos textos parece dialogar con una cita de Ramón del Valle-Inclán que encontramos

Revista Iberoamericana, Vol. LXXX, Núm. 246, Enero-Marzo 2014, $227-240$
ISSN 0034-9631 (Impreso) 
copiada en uno de los cuadernos que conforman el Palais du vocabulaire y que va en el mismo sentido: "No hay diferencia esencial entre el verso y la prosa (...) los grandes poetas eliminan los vocablos vacíos, las apoyaturas, las partículas inexpresivas, y se demoran en las nobles palabras, llenas, plásticas, dilatadas” (APP B.4, f.9, p.23).

Este trabajo de "depuración verbal” al que Pizarnik somete sus textos presenta analogías con el trabajo del escultor que repuja la materia sobrante con su cincel para dejar salir la imagen encerrada en el bloque de mármol. No se trata únicamente de una lucha entre la materia y el espíritu, sino también de una consideración del hecho literario como actividad que también tiene en cuenta el trabajo previo como parte integrante de la obra, como actividad que liberara hasta cierto punto, el sentido "atrapado" en la materia. En definitiva, una consideración del hecho literario que involucra a la vez el plano lingüístico, estético e intelectual.

Si bien en la segunda versión advertimos algunos cambios léxicos ("pasaje” se convierte en "paraje"; "harapientas" se transforma en "desolladas") y una vacilación en la deixis (se incorpora un deíctico de lugar [“aquí yace...”], se omiten algunos deícticos de persona), es en la tercera versión donde, tal vez, se produce la mayor cantidad de transformaciones:

\section{Versión 3: * Cahier LINUS [APP, loc. cit., Box 3, Folder 8, p. 13]}

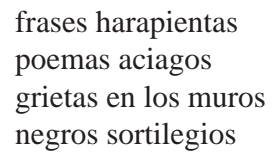

NO

A partir de esta etapa, el blanco se hace cada vez más presente, inscribiendo en la página misma la dimensión temporal del gesto interrumpido, a través de pausas y de intervalos ritmados, vueltos visibles a partir del uso del punto y aparte y la sangría aumentada. Las mayúsculas y la puntuación también han desaparecido, para dar paso a una escritura que se acopla y que está en consonancia con los textos anteriores y posteriores. Se trata, en definitiva, de una escritura que aspira a la continuidad y que, implícitamente, intenta reanudar un discurso ya empezado (de ahí la ausencia de mayúscula inicial) y dejar abierta la posibilidad de una continuación discursiva, que la incorporación de una estrofa suplementaria no hace sino reforzar.

Una vez más, se borran las referencias espacio-temporales o circunstanciales (“Al sol de la infancia”; "aquí yace...”; "noches / de Saint-Paul-de-Vince [sic]”) en favor de una descontextualización (y por lo tanto, universalización) del texto. También los verbos ("tuve"; "me separan”; "me asfixio"; "no quiero") y los pronombres personales de primera persona se eclipsan en este tercer momento, proceso que marca la pérdida

Revista Iberoamericana, Vol. LXXX, Núm. 246, Enero-Marzo 2014, $227-240$
ISSN 0034-9631 (Impreso) 
del carácter narrativo del fragmento y que descarta la marcada subjetividad del poema, que a partir de este momento se acerca más a la sentencia o a la poesía gnómica:

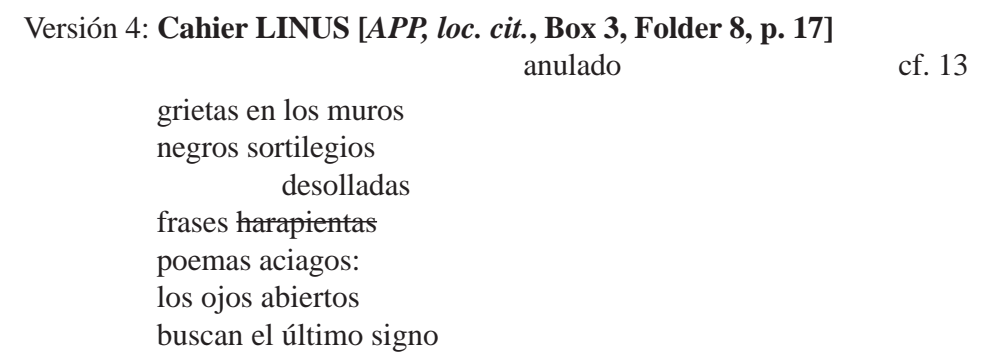

Versión 5: Cahier LINUS [APP, loc. cit., Box 3, Folder 8, p. 19]

los ojos abiertos
buscan el último signo
grietas en los muros
negros sortilegios
frases desolladas
poemas aciagos

p. 13 y 17

como un grito

Versión 6 : Cahier LINUS [APP, loc. cit., Box 3, Folder 8, última página (verso)] aprobados págs 3 -19-

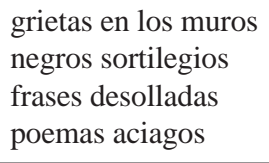

\section{Versión publicada en Árbol de fuego, ํㅜ 45, Caracas, 1971 (Poesía 384)}

Si bien todo el poema parece girar alrededor de la escritura, el recurso a la yuxtaposición sugiere una equivalencia entre los versos que, al aludir a “frases desolladas”, "poemas funestos" o al misterioso poder de las palabras, "sortilegios negros", declinan de distintas maneras el modo en que Pizarnik concibe su propia actividad. Al omitir los conectores lógicos, la parataxis refuerza el carácter ambivalente de los versos y sugiere la idea de una suspensión temporal, de un presente eterno. Las frases nominales, cuyo empleo se hace manifiesto a partir de la tercera versión, refuerzan el tono sentencioso,

\begin{tabular}{l} 
Revista Iberoamericana, Vol. LXXX, Núm. 246, Enero-Marzo 2014, $227-240$ \\
\hline ISSN 0034-9631 (Impreso)
\end{tabular} 
a la vez que fijan la temporalidad en lo inacabado, o incluso en el inmovilismo. Es interesante notar que, además del despojo progresivo del texto, la fluctuación léxica y en particular el cambio de "frases harapientas" (primera, tercera y cuarta versión) por "frases desolladas" (segunda, cuarta y quinta versión) pone de manifiesto dos modos de concebir la escritura: si bien en ambos casos se insiste en la degradación, en el desgarro y el despedazamiento, el primer sintagma pone el acento en la idea del texto como “tejido de voces” (Barthes 1973, 85), es decir, en la textura misma de la frase, mientras que en el segundo caso se alude al aspecto orgánico y “descarnado” de la escritura, que se desprende poco a poco de su corteza para ir descubriendo y retener únicamente el nudo, el centro del poema:

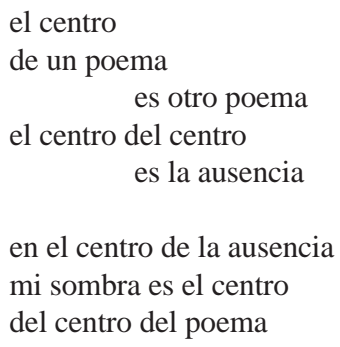

Después de haber experimentado sucesivas correcciones, la prosa inicial termina siendo un "pequeño canto" de apenas cuatro versos de contenido metapoético. Pero, fiel a las leyes de la conservación de la materia formuladas por Lavoisier, Pizarnik ofrece una nueva vida a sus "residuos textuales" a través del desplazamiento y la reintegración de lo descartado en otros proyectos. Así, los restos del principio de la primera versión (“Al sol de la infancia tentra mituve una voz nueva, infusa de muerte, de vida hermosa”) resuenan en un fragmento mecanografiado y luego corregido a mano de la serie inédita "La mesa verde", (fechada 17-IX-72): "Me rememoro al sol de la infancia, infusa de muerte, de vida hermosa" (Poesía 449), del mismo modo que la fórmula "el desaparecido de los siete rostros, el músico”, que había sido más o menos conservada en la segunda versión para luego ser descartada, reaparece en el íncipit de "Canción para el yacente": “Todo el día llora por mí el invisible de siete rostros” (Poesía 368).

Los poemas deAlejandra Pizarnik se nos presentan como un espacio fragmentado por el blanco, como un espacio de versos depurados que resultan de sucesivas campañas de corrección. El trabajo preparatorio no desaparece sino que, por el contrario, se reabsorbe

Revista Iberoamericana, Vol. LXXX, Núm. 246, Enero-Marzo 2014, $227-240$
ISSN 0034-9631 (Impreso) 
en el texto terminado, de modo tal que la selección, el borrado y los diferentes modos de aniquilación de palabras que intervienen en el proceso de escritura quedan de alguna manera incluidos en el resultado final. Así, por ejemplo, el escamoteo de fuentes y de marcos de referencia, la desaparición de toda alusión contextual y el tamizado progresivo de los textos que hemos analizado se relacionan, primero, con la figura retórica de la elipsis en tanto "denegación de un elemento y concentración metonímica de la luz en otro" (Sarduy 186) y, segundo, con el hurgar en lo "velado" y lo "vedado" de los manuscritos y papeles de trabajo, donde permanece todo lo que, por un motivo u otro, fue borrado o suprimido de la superficie textual. En ese sentido, podemos decir que los mecanismos de selección, tachado y borrado que hemos analizado, a los que se suman la reapropiación y la subversión de discursos ajenos, tienen una incidencia determinante en el efecto de "densidad poética" que advertimos al leer los textos de Pizarnik y que resulta de la acumulación y la yuxtaposición de los "restos" o "residuos" textuales que sobreviven al brutal desmembramiento, a las instancias de feroz corrección a las que Pizarnik somete sus textos:

No obstante, no acepto como finalizado a un poema en prosa -por extenso que sea-hasta que no haya pasado por la prueba de fuego de mi duro, lánguido y terrible "método" inventado por mí para martirizarme. Por otra parte, ¿̇para qué diablos la perfección? Si el precio es matar mi voz, mi urgencia, mi premura, si es sólo plasmar y demorar hasta que cada frase es una lápida. Ahora bien: yo quisiera, naturalmente, escribir como yo luego de esas penosas correcciones. Natural o espontáneamente. (Diarios 421)

$\mathrm{Al}$ referirse a la corrección como si se tratara de un instrumento de tortura, Pizarnik no sólo reanuda con la idea de la escritura como sufrimiento o con la idea de la corrección como violencia ejercida sobre el cuerpo de la escritura sino que, tal como se desprende del análisis genético del "pequeño canto" que presentamos, también reniega la práctica de una escritura “automática”, maquinal o instintiva, en pos de una corrección descarnada cuyo objetivo último sería alcanzar la plena posesión del lenguaje a través de la agresión y del embate riguroso: "Cada palabra debe estar llena de polvo, de cielo, de amor, de orín, de violetas, de sudor y de miedo. Cada palabra ha de ser gastada, pulida, retocada, sufrida" (Diarios 92).

\footnotetext{
Revista Iberoamericana, Vol. LXXX, Núm. 246, Enero-Marzo 2014, 227-240 


\section{OBRAS CITADAS}

Aira, César. Alejandra Pizarnik. Rosario: Beatriz Viterbo, 1998.

Barthes, Roland. Essais critiques. París: Seuil, 1964. Le Plaisir du texte. París: Seuil, 1973.

Biasi, Pierre-Marc de. “Qu'est ce qu'une rature?” Rature etrepentirs. Actes du cinquième colloque du Cicada, 1-3 décembre 1994, textos reunidos por Bertrand Rougé. Pau: Publications de l’Université de Pau, 1996. 17-47.

Bioy Casares, Adolfo. Borges. Daniel Martino, ed. Barcelona: Destino, 2006.

Borges, Jorge Luis. Obras completas. Buenos Aires: Emecé, 1974.

Di Ció, Mariana. "Una escritura de papel. Alejandra Pizarnik en sus manuscritos”. Recto/ verso. Revue de Jeunes Chercheurs en Critique Génétique 2: Latinoamérica. Un Eldorado de papiers, Institut des Textes et Manuscrits Modernes (ITEM), diciembre de 2007. <http://www.revuerectoverso.com/spip.php?article73>.

Follet, Lionel. “Apollinaire entre vers et prose”. Semen, 3: La réécriture du texte littéraire, 1987. <http://semen.revues.org/document5523.html>.

Genovese, Alicia. "La proyección del verso". El Cronista Cultural (Buenos Aires, 18 de octubre de 1993): 10.

Ginzburg, Carlo. "Traces. Racines d'un paradigme indiciaire”. Mythes, emblèmes, traces. Morphologie et histoire. París: Flammarion, 1986. 139-80.

Hay, Louis. Les manuscrits des écrivains. París: CNRS Editions/Hachette, 1993.

Herschberg Pierrot, Anne. "Les Manuscrits de Roland Barthes par Roland Barthes, style et genèse”. Genesis: manuscrits, recherche, invention 19: Roland Barthes. París: Jean Michel Place (2002): 191-215.

Le Style en mouvement. Littérature et art. París: Belin-Sup, 2005.

Lois, Élida. Génesis de escritura y estudios culturales. Introducción a la crítica genética, Buenos Aires: Edicial, 2001.

Mallarmé, Stéphane. Divagations. Paris: Fasquelle, 1897: 283-91.

Pizarnik, Alejandra. Alejandra Pizarnik Papers [APP]. Princeton University Library: «Rare Books and Special Collections [RBSC]», Manuscripts Department [C0395]. Correspondencia Pizarnik. Ivonne Bordelois, ed. Buenos Aires: Seix Barral, 1998. Diarios. Ana Becciú, ed. Barcelona: Lumen, [Memorias y biografías], 2003. Poesía completa. Ana Becciú, ed. Barcelona: Lumen, [Poesía 120], 2da ed., 2001. Prosa completa. Ana Becciú, ed. Buenos Aires; Lumen, [Palabra en el tiempo]. 2002.

Requeni,Antonio. “Recuerdo deAlejandra Pizarnik”.Alba de América, Instituto Literario y Cultural Hispánico, Editorial Universitaria Centroamericana 6-7/ 4 (1986): 205-14.

Sarduy, Severo. “Elipsis: Góngora”. Ensayos generales sobre el Barroco. Buenos Aires: Fondo de Cultura Económica, 1987. 186-94.

\footnotetext{
Revista Iberoamericana, Vol. LXXX, Núm. 246, Enero-Marzo 2014, 227-240 ISSN 0034-9631 (Impreso) ISSN 2154-4794 (Electrónico)
} 